\title{
Endoscopic Endonasal Trans-Sphenoidal and Skull Base Surgeries in Aseer Central Hospital, Sothern Saudi Arabia
}

\author{
Abdullah Alskaini ${ }^{1 *}$, Abdulaziz Qobty ${ }^{2}$, Ali Alzaraei ${ }^{3}$ and Khalid Alshehri ${ }^{3}$ \\ ${ }^{1}$ ORL-HNS Residents, Armed Forces Hospital Southern Region,KSA \\ ${ }^{2}$ ORL-HNS Residents, Aseer Central Hospital, KSA \\ ${ }^{3}$ ORL-HNS Consultant, Aseer Central Hospital, KSA
}

Submission: May 13, 2020; Published: May 21, 2020

*Corresponding author: Abdullah Alskaini, ORL-HNS Residents, Armed Forces Hospital Southern Region, KSA

Abstract

Background: Over the Last 20 years, the transsphenoidal approach has been used to remove skull base tumors and also to reconstruct skull base in CSF leakage cases. With the development of endoscope technology and endoscopic surgery, resection of these Skull base tumors, like meningiomas, craniopharyngiomas, and large pituitary adenomas has been achieved by using endoscopic endonasal skull base (EESB) approaches. Many surgeons have reported the usefulness.

Aim: Clinical assessment of endoscopic endonasal skull base surgeries for tumour resection or reconstructive purpose and also to evaluate development of skull base surgeries in southern region of Saudi Arabia.

Methodology: A case series study was conducted in Division of Rhinology, Department of ORL HNS at Aseer central Hospital (ACH), Southern of Saudi Arabia. The study included all patients, who diagnosed with skull base lesion and CSF leakage and undergone endoscopic endonasal skull base surgeries over a period of 6 years. All records for identified cases were reviewed to find out the demographic data and surgeries related data.

Results: The study included 20 cases whose ages ranged from 18 to 66 years old with mean age of 43.316 .6 years old. Exact of $85 \%$ of the bases had tumour and $10 \%$ had traumatic injuries. Intra-operative CSF was recorded among $70 \%$ of the cases and $55 \%$ recorded complications while recurrence was recorded among $25 \%$ of the cases.

Conclusion: In conclusion, the less invasive endoscopic endonasal approach of the skull base and the pituitary fossa is an innovative time saving surgeries with minimal complications. Better training for clinical skills and new techniques was recommended for all concerned surgeons.

Keywords: Endoscopic endonasal surgery; Skull base; Lesions; Tumour; Complications; Non-invasive; Clinical outcome

\section{Background}

The Endoscopic Endonasal Approach (EEA) is a pioneering surgical technique used to remove brain tumors and lesions some as large as softballs all through the nose. This approach needs a multidisciplinary team of neurosurgeons, otolaryngologists, ophthalmic surgeons, and spine surgeons [1,2]. Using EEA, surgeons can achieve tumors and lesions of the skull base and top of the spine directly through the nose and sinuses. Surgeons using EEA approach need a specially designed endoscope, which provides light and a lens for viewing and reflecting internal anatomy. Highly crafted instruments are used alongside the endoscope for tumour dissection then removal $[3,4]$.

This minimally invasive approach uses the nose and sinuses as natural pathway to reach tumors and lesions in critical areas at the base of the skull or top of the spine. The Endoscopic Endonasal Approach allows surgeons to treat many inaccessible tumors, even those once considered "inoperable," without disturbing the face or skull [5,6]. Endoscopic endonasal surgery can reach nearly all regions of the skull base located anterior to the foramen mag- 


\section{Global Journal of Otolaryngology}

num. Tumours are the lesions mainly targeted, but cerebrospinal fluid (CSF) leaks of traumatic or other causes, besides some chronic infections and congenital malformations are also accessible to endoscopic surgery [7-10].

The natural expansion to reach other areas laboured a well-defined anatomy-based modular approaches that access the median ventral skull base (between the ICAs), extending from the crista galli to the odontoid which is known as the "sagittal plane" [11]. Postoperative complications included infectious, systemic, and delayed deficits. These complications were may be potential causes of permanent or transient neurological deficits or even death [12]. As a special point of interest, the incidence of postoperative CSF leaks that recorded and was associated with high patient's morbidity [13]. The current case series study was developed to report the results of a series of patients undergoing pure endoscopic endonasal skull base surgeries for tumour resection or reconstructive purpose and to evaluate initiated skull base surgeries in southern region of KSA.

\section{Methodology}

A case series study was conducted in Division of Rhinology, Department of ORL HNS at Aseer central Hospital (ACH), Southern of Saudi Arabia that is the main tertiary hospital in Abha city, capital of Aseer region. The study included all patients, who diagnosed with skull base lesion and CSF leakage and undergone endoscopic endonasal skull base surgeries over a period of 6 years (from May 2014 to December 2019) and attended for follow up in the outpatient clinic. Patients with skull base lesion and those who had CSF rhinorrhea and undergone transcranial skull base surgeries were excluded. All records for identified cases were re- viewed to find out the demographic data, causes of CSF leakage, clinical presentation, and clinical diagnosis, type of surgery, complications and post-surgical recurrence rate.

\section{Data Analysis}

After data were extracted, it was revised, coded and fed to statistical software IBM SPSS version 22 (SPSS, Inc. Chicago, IL). All statistical analysis was done using two-tailed test. P value less than 0.05 was considered statistically significant. Descriptive analysis based on frequency and percent distribution was done for all extracted variables including demographic data, clinical data, causes of CSF leakage and complications. Univariant relations between patients' bio-clinical data and clinical outcome including complication with recurrence were assessed using crosstabluation method.

\section{Results}

The study included 20 cases whose ages ranged from 18 to 66 years old with mean age of 43.316 .6 years old. Exact of $60 \%$ of the cases were males and 30\% had Acromegaly (Table 1). As for clinical data (Table 2), $85 \%$ of the bases had tumour and $10 \%$ had traumatic injuries. The main complain recorded among the study cases was Headache with blurred vision (50\%) followed with headache with vertigo (15\%) while headache only was recorded among $10 \%$ of the cases. Diagnosis that was dominant among the cases is primary adenoma (65\%) followed with CSF leak (10\%), pituitary micro adenoma (10\%) and only 1 case was Meningioma and pituitary cyst. Considering radiological findings, CT and MRI matched histopathological findings among $80 \%$ of the cases and mismatching was recorded for $10 \%$ of the cases.

Table 1: Personal data of cases undergone pure endoscopic endonasal skull base surgeries in $\mathrm{ACH}$, Saudi Arabia.

\begin{tabular}{|c|c|c|c|}
\hline Bio-Demographic Data & & No & $\%$ \\
\hline \multirow{2}{*}{ Age in years } & $<30$ years & 8 & $40.00 \%$ \\
\hline & $>30$ years & 12 & $60.00 \%$ \\
\hline \multirow{2}{*}{ Gender } & Male & 12 & $60.00 \%$ \\
\hline & Female & 8 & $40.00 \%$ \\
\hline \multirow{4}{*}{ Examination } & Medically free & 12 & $60.00 \%$ \\
\hline & Acromegaly & 6 & $30.00 \%$ \\
\hline & Cushing syndrome & 1 & $5.00 \%$ \\
\hline & Head trauma & 1 & $5.00 \%$ \\
\hline
\end{tabular}

Table 2: Clinical data of cases undergone pure endoscopic endonasal skull base surgeries in ACH, Saudi Arabia.

\begin{tabular}{|c|c|c|c|}
\hline \multirow{2}{*}{ Clinical Data } & & No & \% \\
\hline \multirow{3}{*}{ CSF causes } & Traumatic & 2 & $10.00 \%$ \\
\cline { 2 - 4 } & Spontaneous & 1 & $5.00 \%$ \\
\cline { 2 - 4 } & Tumour & 17 & $85.00 \%$ \\
\cline { 2 - 4 } & Headache & 2 & $10.00 \%$ \\
\cline { 2 - 4 } & Blurred vision & 3 & $15.00 \%$ \\
\cline { 2 - 4 } & Others & 2 & $10.00 \%$ \\
\cline { 2 - 4 } & Headache with blurred vision & 10 & $50.00 \%$ \\
\hline
\end{tabular}


Global Journal of Otolaryngology

\begin{tabular}{|c|c|c|c|}
\hline \multirow{6}{*}{ Diagnosis } & CSF leak & 2 & $10.00 \%$ \\
\hline & Head trauma & 1 & $5.00 \%$ \\
\hline & Meningioma & 1 & $5.00 \%$ \\
\hline & Pituitary adenoma & 13 & $65.00 \%$ \\
\hline & Pituitary micro adenoma & 2 & $10.00 \%$ \\
\hline & Pituitary cyst & 1 & $5.00 \%$ \\
\hline \multirow{4}{*}{ CT and MRI findings } & Matching histopathology & 16 & $80.00 \%$ \\
\hline & Not matching & 2 & $10.00 \%$ \\
\hline & Macro adenoma & 1 & $5.00 \%$ \\
\hline & No mass & 1 & $5.00 \%$ \\
\hline
\end{tabular}

Figure 1 represents the clinical outcome for the different cas-

and $55 \%$ recorded complications while recurrence was recorded es. Intra-operative CSF was recorded among $70 \%$ of the cases among $25 \%$ of the cases.

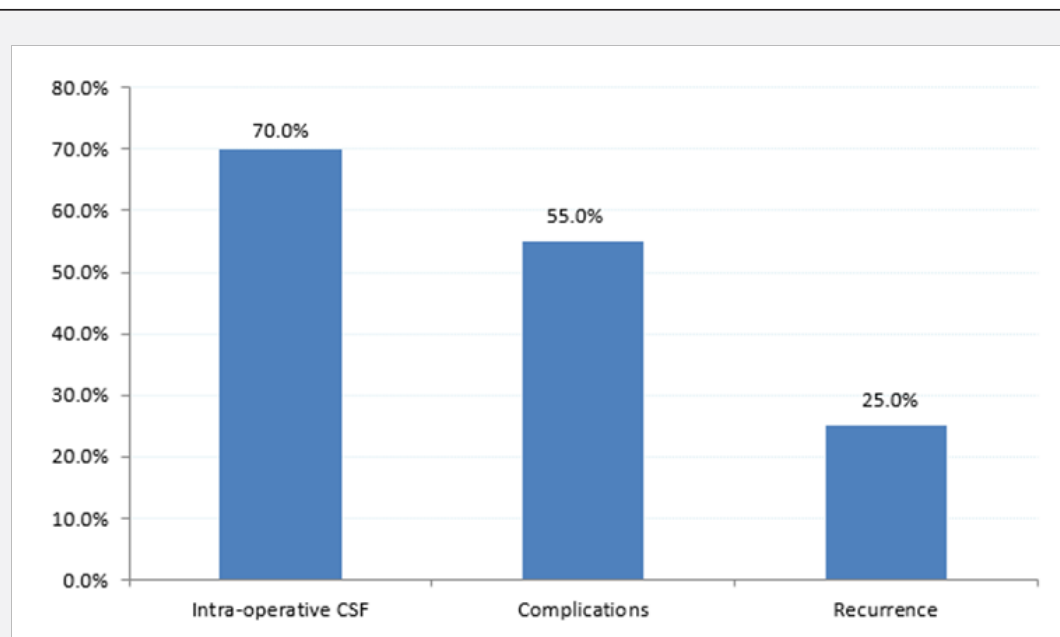

Figure 1: Clinical outcome for cases undergone pure endoscopic endonasal skull base surgeries in ACH, Saudi Arabia.

Table 3: Relation between clinical outcome and bio-clinical data of the cases.

\begin{tabular}{|c|c|c|c|}
\hline \multirow{2}{*}{ Factors } & Intra-operative CSF & Complications & Recurrence \\
\hline & (\%) & (\%) & $(\%)$ \\
\hline \multicolumn{4}{|c|}{ Age in years } \\
\hline$<30$ years & $75.00 \%$ & $50.00 \%$ & $37.50 \%$ \\
\hline$>30$ years & $66.70 \%$ & $58.30 \%$ & $16.70 \%$ \\
\hline \multicolumn{4}{|c|}{ Gender } \\
\hline Male & $58.30 \%$ & $41.70 \%$ & $25.00 \%$ \\
\hline Female & $87.50 \%$ & $75.00 \%$ & $25.00 \%$ \\
\hline \multicolumn{4}{|c|}{ CSF causes } \\
\hline Traumatic & $100.00 \%$ & $100.00 \%$ & $50.00 \%$ \\
\hline Spontaneous & $100.00 \%$ & $100.00 \%$ & $0.00 \%$ \\
\hline Tumour & $64.70 \%$ & $47.10 \%$ & $23.50 \%$ \\
\hline
\end{tabular}

Table 3 demonstrates the distribution of the clinical outcome according to patients' bio-clinical data. Intraoperative CSF was recorded among $75 \%$ of patients aged less than 30 years while $58.3 \%$ of the cases above 30 years had complications and $37.5 \%$ of those aged less than 30 years had recurrence. As for gender, $87.5 \%$ of females had intra-operative CSF and $75 \%$ of them recorded complications while $25 \%$ had recurrence, which is the same for males. With regard to CSF causes, all traumatic and spontaneous 
cases had intra-operative CSF and complications while only $50 \%$ of traumatic had recurrence compared to none of the spontaneous cases. Recurrence was recorded for $23.5 \%$ of tumour cases.

\section{Discussion}

Transcranial skull base approaches were used to resect Midline skull base tumors, such as meningiomas, craniopharyngiomas, and large pituitary adenomas and this approach needed long time [12-16]. Afterwards, this approach was replaced by minimally invasive keyhole approaches through eyebrow incisions for resecting these tumors $[17,18]$. Besides, another approaches used like the microsurgical transsphenoidalsurgeries for skull base tumors $[19,20]$. After development of the endoscopic surgeries, endoscopic endonasal skull base approach was the preferred method for resecting skull base tumours and repairing skull base fractures [21,22].

Many researches told about drawbacks of the invasive or less invasive approaches including trans sphenoidal microsurgical approaches, which had upward trend for skull base surgeries. Surgeons reported that these approaches challenged with restricted viewing angles and limited light intensity with difficulty in achieving gross total tumor resection [23]. These problems were solved even partially by introducing endoscopic surgeries in these approaches. Better visualization of the surgical field with wider viewing angles are the main advantages of this approach [24-26]. Casiano et al. [27] described the first approach of purely endoscopic endonasal surgery for the resection of esthesioneuroblastomas [27]. Since this date, this approach has been widely recognized and repeated for resection of a variety of anterior skull base tumors [28].

Endoscopic endonasal approach appears to be much less painful and much less uncomfortable than comparable traditional approaches. Most patients do not need strong medication to control pain, and are discharged on mild pain relievers. The most common complaint is the post-operative nasal packing's, which are not used all the time and are removed within one week. A recent consensus favours the use of endoscopic techniques in the management of benign tumors including pituitary adenomas, craniopharyngiomas, all besides inverted papilloma's and nasopharyngeal fibromas. Recent studies have validated endonasal management of cholesterol granuloma of the petrous apex and petrous apicitis, congenital malformations (meningoencephaloceles), or CSF leaks, showing a comparable or superior efficacy to conventional open surgery $[29,30]$.

The current study aimed to assess endoscopic endonasal skull base approach in its clinical outcome. The study revealed that the majority of cases undergone the approach were males above 30 years with Acromegaly. Tumour was the most recorded cause with CSF leak so the main complain was headache with blurred vision. The most common diagnosed tumour was pituitary gland adenoma. Complications for the approach was recorded for more than half of the cases with Intraoperative CSF among more than two thirds of the cases while recurrence was recorded for one out of each four cases. Recurrence rate was higher among young aged cases with traumatic lesions.

The new techniques including endoscopic endonasal skull base surgery needs continuous learning skills and collaborative work. Surgeons wishing to conduct this type of surgery should therefore acquire these new techniques in common plus improving their skills including their complementarily which always constitutes a major favour when performing complicated four-hand surgical procedures.

\section{Conclusion}

In conclusion, the minimally invasive endoscopic endonasal approach of the skull base and the pituitary fossa is an innovative time saving surgeries with minimal complications and better resection ability. The collaborative teamwork between the otolaryngologists and the neurosurgeon is vital and valuable in effective resection of cranial base tumors with minimal morbidity complications. A continuous training of the surgeons to cope with new updates and extended methods of this approach is needed with continuous assessment and exploring new fields for its application especially in area with restricted accessibility by the traditional surgical methods.

\section{References}

1. Cappabianca P, Cavallo LM, de Divitiis E (2004) Endoscopic endonasal transsphenoidal surgery. Neurosurgery 55: 933-941.

2. Cavallo LM, Messina A, Gardner P, Esposito F, Kassam AB, et al. (2005) Extended endoscopic endonasal approach to the pterygopalatine fossa: anatomical study and Clinical considerations. Neurosurg Focus 19(1): E5.

3. Hadad G, Bassagasteguy L, Carrau RL, Mataza JC, Kassam A, et al. (2006) A novel reconstructive technique after endoscopic expanded endonasal approaches: vascular pedicle nasoseptal flap. Laryngoscope 116: $1882-1886$.

4. Lund VJ, Stammberger H, Nicolai P, Castelnuovo P, Beal T, Beham A, et al. (2010) European position paper on endoscopic management of tumours of the nose, paranasal sinuses and skull base. Rhinology. Supplement 22:1-43.

5. Zanation AM, Snyderman CH, Carrau RL, Gardner PA, Prevedello DM, et al. (2009) Endoscopic endonasal surgery for petrous apex lesions. The Laryngoscope 119(1): 19-25.

6. Tabaee A, Anand VK, Cappabianca P, Stamm A, Esposito F, et al. (2010) Endoscopic management of spontaneous meningoencephalocele of the lateral sphenoid sinus. Journal of neurosurgery 112(5): 1070-1077.

7. Buchmann L, Larsen C, Pollack A, Tawfik O, Sykes K, Hoover LA (2006) Endoscopic techniques in resection of anterior skull base/paranasal sinus malignancies. The Laryngoscope 116(10): 1749-1754.

8. Stammberger H, Anderhuber W, Walch C, Papaefthymiou G (1999) Possibilities and limitations of endoscopic management of nasal and paranasal sinus malignancies. Acta oto-rhino-laryngologica Belgica 53(3): 199-205.

9. Thaler ER, Kotapka M, Lanza DC, Kennedy DW (1999) Endoscopically assisted anterior cranial skull base resection of sinonasal tumors. American journal of rhinology 13(4): 303-310. 
10. Eloy JA, Vivero RJ, Hoang K, Civantos FJ, Weed DT, et al. (2005) Comparison of transnasal endoscopic and open craniofacial resection for malignant tumors of the anterior skull base. The Laryngoscope 119(5): 834-840.

11. Kassam A, Snyderman CH, Mintz A, Gardner P, Carrau RL (2005) Expanded endonasal approach: the rostrocaudal axis. Part I. Crista galli to the sella turcica. Neurosurgical focus 19(1): 1-2.

12. Kassam A, Snyderman CH, Mintz A, Gardner P, Carrau RL (2005) Expanded endonasal approach: the rostrocaudal axis. Part II. Posterior clinoids to the foramen magnum. Neurosurgical focus 19(1): 1-7.

13. Kassam A, Thomas AJ, Snyderman C, Carrau R, Gardner P (2007) Fully endoscopic expanded endonasal approach treating skull base lesions in pediatric patients. Journal of Neurosurgery: Pediatrics 106(2): 7586.

14. Kinoshita M, Tanaka S, Nakada M, Ozaki N, Hamada J, et al. (2012) What bone part is important to remove in accessing the suprachiasmatic region with less frontal lobe retraction in frontotemporal craniotomies. World Neurosurg 77: 342-348.

15. Hayhurst C, Teo C (2011) Tuberculum sella meningioma. Otolaryngologic Clinics of North America 44(4): 953-963.

16. Yang YM, Wang ZW, Jiang HZ, Sha C, Yuan QG, et al. (2010) Microsurgical management of tuberculum sellaemeningiomas. Zhonghuayixuezazhi 90(33): 2348-2350.

17. Zhang MZ, Wang L, Zhang W, Qi W, Wang R, et al. (2004) The supraorbital keyhole approach with eyebrow incisions for treating lesions in the anterior fossa and sellar region. Chinese medical journal 117(3): 323-336.

18. Fatemi N, Dusick JR, de PaivaNeto MA, Malkasian D, Kelly DF (2009) Endonasal versus supraorbital keyhole removal of craniopharyngiomas and tuberculum sellaemeningiomas. Operative Neurosurgery 64(suppl_5): 269-287.

19. Bowers CA, Altay T, Couldwell WT (2011) Surgical decision-making strategies in tuberculum sellae meningioma resection. Neurosurgical focus 30(5): E1.

20. Ogawa Y, Tominaga T (2012) Extended transsphenoidal approach for tuberculum sellae meningioma-What are the optimum and critical indications? Actaneurochirurgica 154(4): 621-626.
21. Wang Q, Lu XJ, Li B, Ji WY, Chen KL (2009) Extended endoscopic endonasal transsphenoidal removal of tuberculum sellaemeningiomas: a preliminary report. Journal of Clinical Neuroscience 16(7): 889-893.

22. Shin M, Kondo K, Saito N (2012) Neuroendoscopictransnasal surgery for skull base tumors: basic approaches, avoidance of pitfalls, and recent innovations. Neurologia medico-chirurgica 52(10): 697-703.

23. Charalampaki P, Kafadar AM, Grunert P, Ayyad A, Perneczky A (2008) Vascular decompression of trigeminal and facial nerves in the posterior fossa under endoscope-assisted keyhole conditions. Skull Base 18(02): 117-128.

24. Akutsu H, Kreutzer J, Fahlbusch R, Buchfelder M (2009) Transsphenoidal decompression of the sellar floor for cavernous sinus meningiomas: experience with 21 patients. Neurosurgery 65(1): 54-62.

25. McCutcheon IE, Blacklock JB, Weber RS, DeMonte F, Moser RP, et al. (1996) Anterior transcranial (craniofacial) resection of tumors of the paranasal sinuses: surgical technique and results. Neurosurgery 38(3): 471-480.

26. Thaler ER, Kotapka M, Lanza DC, Kennedy DW (1999) Endoscopically assisted anterior cranial skull base resection of sinonasal tumors. American journal of rhinology 13(4): 303-310.

27. Casiano RR, Numa WA, Falquez AM (2001) Endoscopic resection of esthesioneuroblastoma. American journal of rhinology 15(4): 271-279.

28. Liu JK, Eloy JA (2012) Expanded endoscopic endonasal transcribriform approach for resection of anterior skull base olfactory schwannoma. Neurosurgical focus 32(Suppl1): E3.

29. Clark AJ, Cage TA, Aranda D, Parsa AT, Auguste KI, et al. (2012) Treatment-related morbidity and the management of pediatric craniopharyngioma: a systematic review. Journal of Neurosurgery: Pediatrics 10(4): 293-301.

30. Snyderman C, Kassam A, Carrau R, Mintz A, Gardner P, et al. (2007) Acquisition of surgical skills for endonasal skull base surgery: a training program. The Laryngoscope 117(4): 699-705.

\section{Your next submission with Juniper Publishers will reach you the below assets}

- Quality Editorial service

- Swift Peer Review

- Reprints availability

- E-prints Service

- Manuscript Podcast for convenient understanding

- Global attainment for your research

- Manuscript accessibility in different formats

( Pdf, E-pub, Full Text, Audio)

- Unceasing customer service

Track the below URL for one-step submission https://juniperpublishers.com/online-submission.php 